\title{
Research on Quality Evaluation of Imported Excavator
}

\author{
Shen $\mathrm{Xu}^{1, \mathrm{a}^{*}}$ \\ ${ }^{1}$ Nanjing Communications Institute of Technology Nanjing, 211188,China \\ a1569642399@qq.com \\ * the corresponding author
}

Keyword: Imported used excavator; Whole machine quality; Quality evaluation.

\begin{abstract}
The high-end users generally choose joint venture brands or foreign brand products, the low-end users will generally choose domestic brands or second-hand excavator, excavator second-hand price is generally lower than the domestic excavator, but the reliability and other performance advantages are sometimes more than domestic machines, "it should be easy to use" has become the best publicity signs of imported second-hand excavator. Imports of second-hand excavators flooded the market, resulting in the excavator market mixed. In recent years, a lot has been used for many years overseas influx of second-hand excavator Chinese market, on the one hand to the already fierce competition in the China excavator market adds more uncertainty; on the other hand, the import of second-hand excavator into Chinese market lack or effective inspection methods and means, resulting in uneven quality of imported second-hand excavators in order to protect the interests of the state,! To ensure the legitimate rights and interests of consumers, to ensure production safety, carry out effective inspection of imported second-hand mining, it is necessary to establish a quality evaluation system.
\end{abstract}

\section{Introduction}

For imported second-hand excavators and related policies, the domestic excavator industry is no stranger. It is understood that in the early 1990s, China's imports of old mechanical and electrical products lower threshold, foreign second-hand excavators gradually entered the Chinese market. Imported second-hand excavators have rapidly occupied the market with their cost-effective advantages, and the market share has been rising continuously. In 1998, the main excavator domestic manufacturers jointly to the relevant departments of the state sent a letter, put too much impact on domestic and imported second-hand excavator excavator manufacturers market, need to regulate the import of second-hand excavator. The relevant departments of the state accepted the proposals and raised the threshold for imports of used excavators. In the eastern coastal areas, second-hand excavators made by importing and smuggling through formal channels have made the domestic excavator market shrink rapidly, and the imported second-hand excavators have caused great damage to the excavator industry in our country. Some import dealers is ignoring the interests of users, at a very low price from the overseas market acquisition of scrap sold to domestic excavator, shoddy. The quality of many old excavators can not be guaranteed, the noise, exhaust emissions, appearance and safety performance are not in line with the relevant standards, there are serious security risks and noise and excessive exhaust emissions and other issues.

\section{Introduction of Imported Second-hand Excavators}

In the past 10 years, the total sales volume of China's excavator market has increased at an average rate of $30 \%$ per year. Fig. 1 shows the total sales figures of the Chinese excavator market over the years. You can see from Fig.1, from 1999 to 2010, the total domestic sales of excavator basic to maintain upward momentum, total sales increased 21 times, which in 2009 to achieve a breakthrough, the total sales reached 101559 units in 2010 , the total sales volume increased to 125630 . 


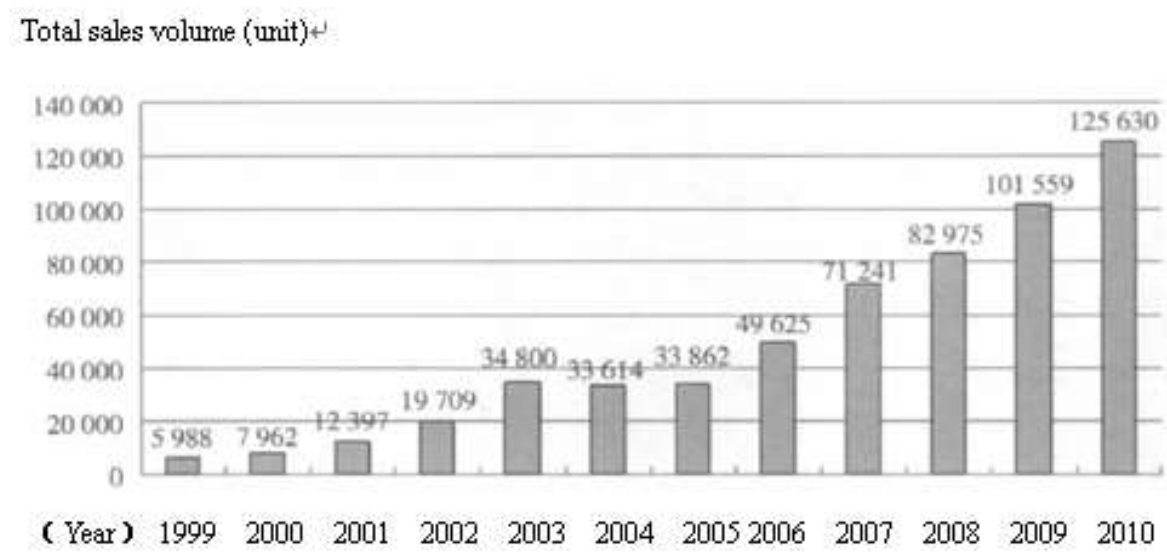

Figure 1. Domestic excavator sales figures in previous years

\section{Imported Second-hand Excavator Problems}

There are many problems in the imported excavators. Understanding and analyzing these problems will be helpful to find the appropriate techniques, methods and means to test the imported excavators effectively. In general, imports of second-hand excavators have the following problems:

Qualities Without Warranty. After several years, some parts imported second-hand excavator has serious wear, the performance index is greatly reduced, and the import link without professional technical personnel and inspection checks, lack of effective methods and means, resulting in second-hand mining machine there are a lot of quality problems in domestic.

Serious Harm to the Environment. Due to the decline in emissions, noise, oil imports of second-hand excavator sealing, material degradation and other indicators, is bound to affect the domestic environment, in addition, but also consider the impact on the environment of dismantling scrapped!

Economic Losses. On the one hand, a large number of tax losses; on the other hand, it is a serious crowding out the living space of the domestic excavator brand, and to some extent, cause the national economic losses.

\section{Evaluation of Imported Second-hand Excavator Quality of the Technical Means of Analysis}

Design of Inspection Plan. Based on the working principle of the excavator, combined with the work of the excavator, starting from environmental protection, safety, performance and other aspects, evaluate the quality of imported second-hand excavator, and further optimize the evaluation of the project, and ultimately the formation of imported second-hand excavator quality evaluation system, to evaluate the quality of imported second-hand excavator with scientific and unified method and application the. Specifically, the evaluation system is divided into 3 levels: one is around the machine check; two is the performance test: including the speed of hydraulic cylinder, rotating and braking performance, track speed; three is the instrument detection: including emission detection, noise detection, oil test, hydraulic test, vibration analysis, testing and other deep inspection institutions and to find the potential quality problems or safety hazards

Data Analysis. Draw 20t imported second-hand excavators, a total of 20 units, $12 t$ imported second-hand excavator 8 units for inspection!

Performance Check. Check the operation of the various components of the detected imported second-hand excavator based judgment! Properties examined include boom cylinder telescopic speed bucket rod hydraulic cylinder "bucket cylinder and track speed check. 20t imported second-hand excavator telescopic arm hydraulic cylinder speed test results! Because the port inspection need rapid detection, this paper measured the speed of hydraulic cylinder hydraulic cylinder in between two extreme positions at full throttle operation, namely the type test of hydraulic cylinder single action time were delineated in the provisions of the sample manufacturers of boom hydraulic models the normal value of cylinder speed and overhaul value. Once 
that exceeds the value, the machine needs to be overhauled before it can be used properly. Test found that almost all of the hydraulic cylinder hydraulic speed is not qualified, which to some extent shows that imported second-hand excavator performance indicators are not optimistic. Analysis of seized imported second-hand excavator parts and different operation speed of hydraulic cylinder is not qualified, only bucket hydraulic cylinder out when the situation is slightly more optimistic, the unqualified parts and other corresponding actions are more serious. This reflects the overall quality of imported excavators is not very good, which means that the imported excavator parts may exist serious wear and tear, etc., need to further use of equipment for analysis and diagnosis.

Oil Detection. Oil plays an important role in the excavator working process, so through the analysis of the oil situation, to some extent can judge the wear machine, found some problems exist in the interior of the machine and potentially dangerous. The wear of the concept, analysis of performance indicators and before the combination can be determined by the state of excavator content analysis of metal elements in oil! The total time for action cycle definition of excavator boom arm and bucket, track, rotary disc and all parts of a cycle respectively. Because the design of different brands of the excavator engine, the main pump is different, different parts of the various components of the materials used are not the same, through comparative analysis, no matter what brand of excavator, the wear degree and the action cycle is directly related to the work cycle is long, wear windspeed, equipment condition worse.

Emission. Emissions are not only environmental protection requirements, but also reflect the situation of imported second-hand excavator engines. Because the emission is based on the power requirements, the discharge is classified according to the tonnage of the excavator. For the 20t excavator, $31.25 \%$ of the imported second-hand excavators can not meet the requirements of phase I emission. At the same time, $31.25 \%$ of the imported second-hand excavators can not meet the emission requirements of phase ii. For the $12 t$ excavators, $62.50 \%$ of the imported second-hand excavators can not meet the requirements of phase II emissions.

Noise. According to the relevant regulations to implement the test, it is found that all the noise of the imported second-hand excavators are in line with the standard requirements.

Nondestructive Inspection of Structural Parts. The performance of excavator working device is one of the important indexes to evaluate the performance of excavator, especially imported second-hand excavator, performance of the working device is related to production safety, so the working device on the import of second-hand excavator for nondestructive testing is very necessary. But the import of second-hand excavator working device of the volume is very large, for each area of NDT is clearly not possible to determine the non-destructive inspection of some key areas, not only can improve the work efficiency, and ensure the reliability of detection. The analysis process can use the three-dimensional model of imported second-hand excavator working device to establish the software, using finite element analysis software for stress and strain analysis, determine the distribution of stress and strain, as specified in the direction of nondestructive detection. It is found that the average stress cloud of the working device is analyzed by taking a hydraulic excavator as an exampleMap can be seen in the work of the working device of excavator, the maximum stress point respectively in the boom cylinder pin "boom hydraulic cylinder is connected at the upper and lower sides of the weld" arm is connected to the front end of the bucket rod Delta "bucket rod hydraulic cylinder is connected to the base of the bucket rod and a movable arm the connecting pin and the inner surface of the bucket rod, the results and related literature on excavator static analysis results similar. As long as the measured hydraulic oil pressure and flow of hydraulic oil, you can determine the measured output efficiency of imported second-hand excavator, in order to determine the internal machine wear! Imported second-hand excavator power output efficiency is low, the engine of the hydraulic pump distribution valve and the hydraulic cylinder parts to wear more. Other parts of a lot of wear and tear may also lead to reduced efficiency, although it can not accurately determine the specific location, but in terms of overall efficiency to determine the status of imported second-hand excavator is still relatively effective. Compared with hydraulic output performance of new machines and imported second-hand excavator can be seen, the hydraulic efficiency of the new machine is much higher than the imported second-hand excavator, this result is mainly due to wear of imported second-hand excavator engine or a hydraulic system caused by. 
Evaluation Index. The above test contents are reflected in one or more aspects of imported second-hand excavator, but ultimately to judge the quality of a imported second-hand excavator, there should be an evaluation index, and make the judgment according to the evaluation index. With the principle of simple and practical, the evaluation system of imported second-hand excavator can be composed of 5 aspects, such as hydraulic cylinder speed, oil test results, discharge, nondestructive testing and hydraulic performance. The correction method is in accordance with the sample in a test project of excavator is abnormal, the probability of summing up the associated parts of the problem, then the cost and probability of the combination of replacement parts completely evaluated! Corrected aims to more accurately reflect the state of the machine, because only a part of some indicators of the corresponding test project such as, only reflect the emission of the engine! But there are also reflected a number of components, such as hydraulic cylinder speed reflects the engine main pump distribution valve hydraulic cylinder "several parts of the situation, the speed of hydraulic cylinder is not up, may be a part of the problem, it may be several parts have problems, but these problems can not be unlimited zoom, and not be able to pay the cost of a few parts to completely replace the simple addition of these indexes for evaluation! It is convenient to judge the whole condition of an imported excavator in an unknown state and to judge its quality accurately!

\section{Summary}

This research project is based on the quality evaluation system of imported second-hand excavator, the quality evaluation system can overall quality status on the import of second-hand excavator to make relatively accurate judgments, make up for the deficiency and shortage in the aspect of quality evaluation methods and means of the import of second-

\section{Acknowledgments}

This work was financially supported by research funding for high-level talents at Nanjing Communications Institute of Technology.

\section{References}

[1] López-Guerrero,A.L.,Martínez-Lage,J.F.,González-Tortosa,J. et al.Pediatric crushing head injury: Biomechanics and clinical features of an uncommon type of craniocerebral trauma[J].Child's nervous system: ChNS : official journal of the International Society for Pediatric Neurosurgery,2012,28(12):2033-2040.

[2] Cao, Yunxing,Qiu, Jianwu,Wang, Bing et al.The Analysis on Risk Factors and Clinical Treatment of Craniocerebral Injury Concurrent with Acute Kidney Injury[J].Cell biochemistry and biophysics,2015,71(1):199-204.

[3] Xu, Guangtao,Hu, Bo,Chen, Guiqian et al.Analysis of Blood Trace Elements and Biochemical Indexes Levels in Severe Craniocerebral Trauma Adults with Glasgow Coma Scale and Injury Severity Score[J].Biological trace element research.,2015,164(2):192-197.

[4] D.C. Brooker.Experimental puncture loads for external interference of pipelines by excavator equipment[J].International Journal of Pressure Vessels and Piping,2005,82(11):825-832.

[5] Joseph Akyeampong,Silvanus Udoka,Giandomenico Caruso et al.Evaluation of hydraulic excavator Human-Machine Interface concepts using NASA TLX[J].International Journal of Industrial Ergonomics, 2014, 44(3) :374-382. 